\title{
Managing supply chain resilience in the era of VUCA
}

\author{
(C) Higher Education Press 2021
}

\section{Introduction}

Today's world has become volatile, uncertain, complex, and ambiguous (VUCA). In such a world, supply chains not only are embedded in VUCA environments but also increasingly exhibit VUCA features. A widely recognized description of the characteristics of VUCA was developed by Bennett and Lemoine (2014), outlined in the following. Volatility: An event encountered by a supply chain is unexpected or unstable; however, information on such an event is available and its impact is generally predictable. Uncertainty: The cause and effect of an event encountered by a supply chain are known; however, other information about the event is unavailable. Complexity: Both the environment and the supply chain itself have many interconnected parts and variables; hence, connecting the cause and effect of an event is very difficult. Ambiguity: An event encountered by a supply chain is unexpected; moreover, the causal relationships are also completely unclear. With the rapid development of the global economy and deep cooperation among global enterprises, supply chains now involve numerous interdependent and interconnected actors located in different countries (Anbumozhi et al., 2020), generating sizable flows of materials, funds, and information between actors (Bode and Wagner, 2015) and forming highly complex network structures (complexity) (Bier et al., 2020). The increasing complexity brings greater volatility and uncertainty to supply chains, resulting in greater ambiguity (Simangunsong et al., 2012; Mack and Khare, 2016). The VUCA environment,

Received May 10, 2021

Ying GAO, Shuibo ZHANG

College of Management and Economics, Tianjin University, Tianjin 300072, China

\section{Zhuo FENG (ه)}

School of Economics and Management, Dalian University of Technology, Dalian 116024, China

E-mail: zhfeng@dlut.edu.cn

This work was supported by the National Natural Science Foundation of China (Grant Nos. 72031008, 71901161, and 71702020). together with the VUCA features of the supply chain itself, exacerbates the possibility of its disruption (Chowdhury and Quaddus, 2017). Given that many disruption risks are even "unknown unknowns", the traditional risk management framework of "identification - evaluation - response - monitoring" is insufficient to counteract them. Instead, building a resilient supply chain has become an important tool to better respond to disruption risks. It has been acknowledged that the strong management of supply chain resilience is able to yield competitive advantages for firms (Tukamuhabwa et al., 2015; Dubey et al., 2021).

\section{Supply chain resilience: Concept, measurement, and strategies}

The concept of "supply chain resilience" was introduced by Rice and Caniato (2003), and a formal definition was first proposed by Christopher and Peck (2004), namely, "the capacity of a system (supply chain) to return to its original state or move to a new, more desirable state after being disturbed". Subsequently, different definitions of supply chain resilience were developed. However, a consensus has been made among scholars that supply chain resilience represents "the adaptive capability of the supply chain to prepare for unexpected events, respond to disruptions, and recover from them" (Ponomarov and Holcomb, 2009). Scholars have also developed different metrics to evaluate supply chain resilience, which can be divided into four categories: (1) measurement based on the supply chain's key capabilities, such as flexibility, visibility, and velocity capability (Chowdhury and Quaddus, 2017; Zouari et al., 2021); (2) measurement based on direct quantitative metrics, such as the time to recovery, recovery level, and loss of supply chain performance during the recovery period (Behzadi et al., 2020); (3) measurement through performance metrics, such as customer service level, market share, and financial performance after a disruption (Hohenstein et al., 2015); and (4) measurement based on the topological indicators of a supply chain network. For instance, supply chain resilience can be 
calculated by the total number of node/arc disruptions not resulting in a supply network disruption divided by the total number of node/arc disruptions (Kim et al., 2015).

As compared with defining and measuring supply chain resilience, the main focus of the existing literature lies in the strategies for supply chain resilience improvement. These strategies can be broadly divided into two categories, namely, proactive and reactive strategies; while the former aims to prepare for a disruption rather than respond to it, and the latter aims to recover a supply chain after a disruption (Tukamuhabwa et al., 2015; Chowdhury and Quaddus, 2017). Proactive strategies have been identified from various perspectives, such as network structure design (Rezapour et al., 2017), appropriate supplier selection (Hosseini et al., 2019b), redundancy (Ponis and Koronis, 2012), flexibility (Jüttner and Maklan, 2011), diversification (Namdar et al., 2018), and building social capitals (Johnson et al., 2013). The attention given to the reactive strategies has been relatively fewer (Tukamuhabwa et al., 2015). However, an increasing number of scholars are becoming aware that digital technology, such as cloud computing and blockchain, may offer a reactive strategy to foster supply chain resilience because it can improve visibility, anticipation, and adaptability (Dubey et al., 2021; Ju et al., 2021; Zouari et al., 2021).

\section{Theoretical underpinnings and research methodology on supply chain resilience}

A number of theories have been applied to supply chain resilience. Kochan and Nowicki (2018) identified more than 20 theories through an extensive literature review. Among these theories, the most commonly used are resource-based view (RBV), dynamic capability theory, relational view, and complexity theory/complex adaptive systems (Ali and Gölgeci, 2019). RBV argues that the ability and competitive advantage of an enterprise come from the valuable, scarce, and irreplaceable resources it possesses (Barney, 2001). Therefore, to enhance supply chain resilience in an unstable environment, firms need to constantly integrate, construct and reallocate internal and external resources. However, RBV looks at supply chain resilience by taking a static perspective and ignores environmental dynamics. As a result, dynamic capability theory and relationship view are used to study which capabilities of firms are required and which relationship should be developed to realize supply chain resilience in a rapidly changing business environment (Wieland and Marcus Wallenburg, 2013; Chowdhury and Quaddus, 2017; Yu et al., 2019). With increasing attention given to the complexity of the supply chain, the complexity theory/ complex adaptive system theory is increasingly adopted. This theory argues that supply chain firms are selforganized and self-adaptive. Therefore, the adaption of firms and the whole supply chain to the dynamic environment results from firms' evolution nonlinearly with the external environment in a complex rule (Tukamuhabwa et al., 2015). In an analysis of the theoretical perspectives used in the existing literature, it is found that most of the articles have a single underpinning theoretical perspective (Ali and Gölgeci, 2019).

Supply chain resilience is studied through a variety of research methodologies, which can be divided into three categories. First, many scholars note the importance of supply chain resilience and focus on the development of a conceptual framework to build resilience in different contexts (e.g., Ponomarov and Holcomb, 2009). Second, quantitative modeling is also widely adopted. Related methodologies include mathematical modeling, decision analysis, network modeling, and simulation (Kochan and Nowicki, 2018; Ali and Gölgeci, 2019). These methodologies are adopted for different topics. Specifically, the adoption of mathematical modeling, including multiobjective linear programming, stochastic programming, and goal programming, enables the study of the optimal supply chain structure to build resilience (Klibi and Martel, 2012); the adoption of decision analysis, including multicriteria analysis, analytic hierarchy process, and network analysis, provides the evaluation of supply chain resilience (Hosseini et al., 2019a); the adoption of network modeling, including Bayesian network, graph modeling, and clustering supply chain network model, characterizes the effect of interactions among network actors on supply chain resilience (Macdonald et al., 2018); and the adoption of simulation, including agent-based simulation and discrete event simulation, facilitates solutions to large scale optimization problems (Kim et al., 2015). Third, the empirical studies such as case studies and surveys are relatively fewer but are growing. The main focus of these studies is in studying the antecedents and consequences of supply chain resilience (Yu et al., 2019) and the development of resilience metrics (Chowdhury and Quaddus, 2017).

\section{Future research on supply chain resilience in the era of VUCA}

Even though the research on supply chain resilience is growing, the understanding of this topic is far from mature and there are still numerous problems to be addressed, especially in the era of VUCA. As a matter of fact, the four components of VUCA, as described above, correspond to different risk categories. With a view to designing and optimizing supply chain resilience, we now use the VUCA framework to discuss below the mitigation strategies under each risk category and propose further research directions, as shown in Fig. 1.

In a volatile world, information about both the probability and the impact of a given risk may be available. Supply chain members should devote resources to 


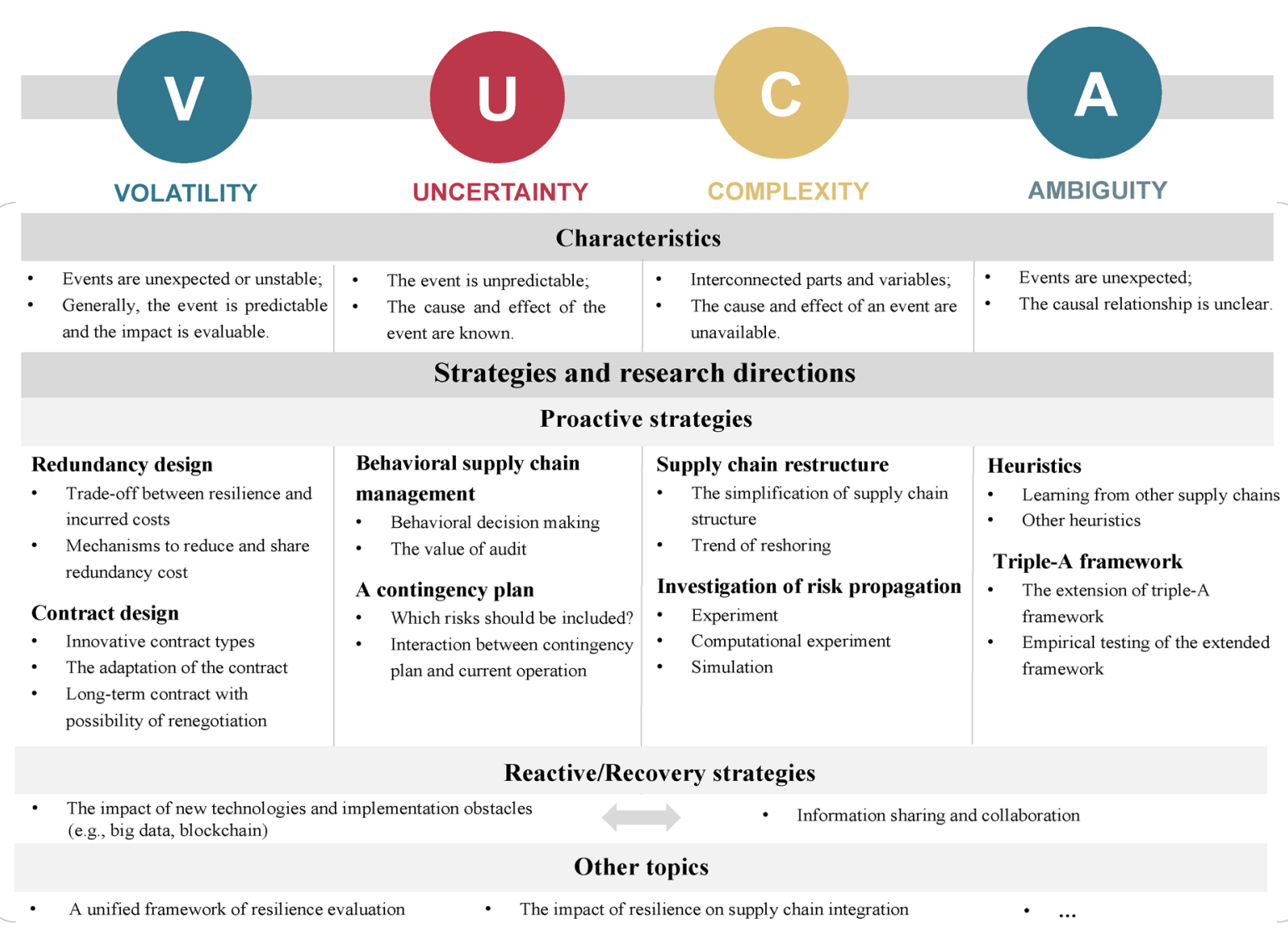

Fig. 1 Summary of future research on supply chain resilience in the VUCA era.

addressing risks with small probabilities. Reserving some redundancies, like overstocking or backup suppliers, has been widely recognized as an important strategy in building supply chain resilience (Hosseini et al., 2019a). However, greater redundancy implies higher costs. Therefore, a trade-off between increases in supply chain resilience and the incurred costs needs to be made. Although scholars are already attempting in this direction (e.g., Ivanov et al., 2014), a systematic framework has not yet been developed. Moreover, future research can also explore the novel mechanisms to reduce the redundancy cost. For example, to overcome the bullwhip effect, the supply chain members can build the redundancy together and share the cost correspondingly. However, effective cost-sharing mechanisms are still lacking. Contract design is another means of risk mitigation. A long tradition in supply chain management adopts contract design to realize certain aims, such as supply chain coordination (Chen et al., 2012). In a volatile environment, contract design needs to fulfill another aim of fair risk allocation among supply chain members. Therefore, innovative contract types or clauses should be created. Future research can investigate how the consideration of resilience affects the traditional value of supply chain contracts. Moreover, in addition to the characteristics of control and coordination, long-term contracts should also exhibit the characteristic of adaptability; that is, when some risks materialize, the contract can be renegotiated to adapt to the new environment. Future research can investigate, in anticipation of future renegotiation, how the contract should be designed in the first place.

In an uncertain world, the probability of a risk is not known, but knowledge of its impact is available. Risks that arise from human decisions typically fall into this category. Addressing risks in an uncertain world requires a continuing emphasis on behavioral supply chain management. This stream of literature mainly focuses on the development of a more realistic framework to characterize the practice by challenging traditional assumptions, such as fully rational supply chain members. In an uncertain world, the behavioral decisions of supply chain members should be carefully studied. This is because an inside event of a supply chain member may disrupt the whole supply chain. Moreover, information collection strategies, such as audits, should also be explored so that supply chain members' inappropriate behaviors can be avoided. A contingency plan suggested by the previous literature would be also helpful, considering that the probabilities of risks that disrupt the supply chain are not obtainable. Under a contingency plan, how to respond to each risk when it materializes is outlined in advance. However, fully preparing for each risk is impossible, and "which risks 
should be included into the contingency plan" remains unanswered. Moreover, when the contingency plan is initiated, it may affect the current supply chain operation by competing for resources. Future research also needs to understand the interaction between a contingency plan and the current supply chain operation.

In a complex world, how risk can disrupt the supply chain is not known but the probability of its occurring is available. Supply chain structures are becoming increasingly complex, with supply chain members located in different countries with heterogeneous institutional environments, regulations, and logistics systems. Therefore, a small risk faced by one supply chain member may eventually lead to the failure of the whole supply chain, i.e., the so-called ripple effect. To reduce complexity, the supply chain can be restructured, and studies have been productive in this direction. However, knowledge of the underlying mechanisms of risk propagation across different supply chain structures remains lacking. Practically, to respond to the increasingly unexpected risks, the trend of reshoring has emerged. Instead of continuing the strategy of offshoring to take advantage of low production costs, an increasing number of global firms are opting to reshore some production to their home countries. This process simplifies their supply chains and allows the risks to be better monitored. The resulting research questions include how much production should be moved into the firm's home country and what impact reshoring has on its competitive advantage. If it is difficult to simplify the structure of a supply chain, the cause and effect relationship should be uncovered to understand how an event affects the whole supply chain. To achieve this aim, an experiment can be performed in a highly controlled environment, with the experimental results being used to inform policymaking. In addition to the experiment, the effectiveness of other methodologies or their combinations in dealing with complexity also needs to be examined by future research such as computational experiments or simulation techniques.

In an ambiguous world, neither the probability nor the impact of a risk is known. Therefore, the supply chain faces "unknown unknowns". At present, an increasing number of events are being encountered by supply chain members for the first time, and dealing with these "unknown unknowns" would become "a new normal" for them. An ongoing example is the COVID-19 pandemic, which was generally unexpected by each supply chain member. In addressing risks in an ambiguous world, other subjects may lend help. For instance, the reference point method, widely practiced in project management, could provide some implications. Even when some risks are new for a given supply chain, they may have been experienced by other supply chains. As a result, the accumulated experiences could be transferred to the supply chain to enable it to deal with its own "unknown unknowns". Transferring knowledge as heuristics enables faster learning of the supply chain. Future research can study the effectiveness of such a method in the subject of supply chain management, and supply chain researchers should proactively find inspiration from wisdom in relevant subjects. Researchers also need to reconsider the triple-A (agility, adaptability, and alignment) framework, which Lee (2004) proposed as an answer to "what are the attributes of the best performing supply chains". This framework was developed based on the long-term observation of several companies and industries. However, the triple-A framework was developed with the aim of achieving supply chain efficiency. In the ambiguous environment, the supply chain faces more and more "unknown unknowns". Thus, the triple-A framework needs to be extended to help supply chains respond to the increasing shocks. A recent extension was developed by Cohen and Kouvelis (2021), which included R, referring to enhanced agility for robustness, adaptability and resilience, and re-alignment. The effectiveness of this extension still needs empirical testing, and future research should also attempt to develop competing extensions.

In the VUCA world, not all risks can be ex ante prevented and proactively mitigated. If a risk that is unprepared for materializes and leads to disruption, a resilient supply chain should have the capacity to make a quick recovery. Rich discussions on this topic have been made, such as strategies of information sharing and collaboration. In addition, to further these discussions, future research should also explore the value of new technologies in supply chain recovery. For example, how big data can help the disrupted supply chain members to quickly find the available suppliers in the market; even though it has been well recognized that the blockchain technology is able to facilitate information sharing and trust-building, the obstacles to implementing blockchain during supply chain recovery remain unknown. It should be noted that the equipment of new technology may require a new set of capabilities of firms. The dynamic capability building to match the adoption of new technologies so that the supply chain can be quickly recovered will be another research direction.

The future directions given above mainly focus on how supply chain resilience can be built in response to different risk categories in the VUCA world. Some other topics are also worth studying. An immediate one is that when multiple strategies are available in building supply chain resilience, which one should be adopted. The evaluation of supply chain resilience is another example. Researchers are using different metrics to evaluate supply chain resilience, potentially leading to contradicting results. How to unify these results awaits answers. The effect of supply chain resilience on supply chain integration is also an important topic. If the supply chain resilience is weighted more than supply chain efficiency, then the boundary of each supply chain firm may need to be reconsidered. In studying supply chain resilience, a systematic view should be adopted; 
that is, supply chain resilience should not be built in fragmentation, but rather be considered as a whole in a coopetition environment. This is because, on the one hand, risks propagate along the supply chain; on the other hand, resilience-building is cost-intensive. Moreover, multidisciplinary research and multiple methodologies are required to effectively build supply chain resilience because supply chain management is not the only subject that becomes vulnerable in the era of VUCA. We believe that the focus on supply chain resilience not only serves as a complement to traditional supply chain theories but also is expected to serve as a catalyst in building new supply chain theories in this VUCA era.

\section{References}

Ali I, Gölgeci I (2019). Where is supply chain resilience research heading? A systematic and co-occurrence analysis. International Journal of Physical Distribution \& Logistics Management, 49(8): 793-815

Anbumozhi V, Kimura F, Thangavelu S M (2020). Global supply chain resilience: Vulnerability and shifting risk management strategies. In: Anbumozhi V, Kimura F, Thangavelu S M, eds. Supply Chain Resilience. Singapore: Springer, 3-14

Barney J B (2001). Resource-based theories of competitive advantage: A ten-year retrospective on the resource-based view. Journal of Management, 27(6): 643-650

Behzadi G, O’Sullivan M J, Olsen T L (2020). On metrics for supply chain resilience. European Journal of Operational Research, 287(1): 145-158

Bennett N, Lemoine G J (2014). What VUCA really means for you. Harvard Business Review, 92(1/2): 27

Bier T, Lange A, Glock C H (2020). Methods for mitigating disruptions in complex supply chain structures: A systematic literature review. International Journal of Production Research, 58(6): 1835-1856

Bode C, Wagner S M (2015). Structural drivers of upstream supply chain complexity and the frequency of supply chain disruptions. Journal of Operations Management, 36(1): 215-228

Chen J, Zhang H, Sun Y (2012). Implementing coordination contracts in a manufacturer Stackelberg dual-channel supply chain. Omega, 40(5): 571-583

Chowdhury M M H, Quaddus M (2017). Supply chain resilience: Conceptualization and scale development using dynamic capability theory. International Journal of Production Economics, 188: 185-204

Christopher M, Peck H (2004). Building the resilient supply chain. International Journal of Logistics Management, 15(2): 1-14

Cohen M A, Kouvelis P (2021). Revisit of AAA excellence of global value chains: Robustness, resilience, and realignment. Production and Operations Management, 30(3): 633-643

Dubey R, Gunasekaran A, Childe S J, Fosso Wamba S, Roubaud D, Foropon C (2021). Empirical investigation of data analytics capability and organizational flexibility as complements to supply chain resilience. International Journal of Production Research, 59(1): 110-128
Hohenstein N O, Feisel E, Hartmann E, Giunipero L (2015). Research on the phenomenon of supply chain resilience: A systematic review and paths for further investigation. International Journal of Physical Distribution \& Logistics Management, 45(1/2): 90-117

Hosseini S, Ivanov D, Dolgui A (2019a). Review of quantitative methods for supply chain resilience analysis. Transportation Research Part E: Logistics and Transportation Review, 125: 285-307

Hosseini S, Morshedlou N, Ivanov D, Sarder M D, Barker K, Khaled A A (2019b). Resilient supplier selection and optimal order allocation under disruption risks. International Journal of Production Economics, 213: 124-137

Ivanov D, Sokolov B, Dolgui A (2014). The ripple effect in supply chains: Trade-off "efficiency-flexibility-resilience" in disruption management. International Journal of Production Research, 52(7): 2154-2172

Johnson N, Elliott D, Drake P (2013). Exploring the role of social capital in facilitating supply chain resilience. Supply Chain Management, 18(3): 324-336

Ju Y, Hou H, Yang J (2021). Integration quality, value co-creation and resilience in logistics service supply chains: Moderating role of digital technology. Industrial Management \& Data Systems, 121(2): 364-380

Jüttner U, Maklan S (2011). Supply chain resilience in the global financial crisis: An empirical study. Supply Chain Management, 16(4): 246-259

Kim Y, Chen Y S, Linderman K (2015). Supply network disruption and resilience: A network structural perspective. Journal of Operations Management, 33-34: 43-59

Klibi W, Martel A (2012). Modeling approaches for the design of resilient supply networks under disruptions. International Journal of Production Economics, 135(2): 882-898

Kochan C G, Nowicki D R (2018). Supply chain resilience: A systematic literature review and typological framework. International Journal of Physical Distribution \& Logistics Management, 48(8): 842-865

Lee H L (2004). The triple-A supply chain. Harvard Business Review, 82(10): 102-112, 157

Macdonald J R, Zobel C W, Melnyk S A, Griffis S E (2018). Supply chain risk and resilience: Theory building through structured experiments and simulation. International Journal of Production Research, 56(12): 4337-4355

Mack O, Khare A (2016). Perspectives on a VUCA world. In: Mack O, Khare A, Krämer A, Burgartz T, eds. Managing in a VUCA World. Cham: Springer, 3-16

Namdar J, Li X, Sawhney R, Pradhan N (2018). Supply chain resilience for single and multiple sourcing in the presence of disruption risks. International Journal of Production Research, 56(6): 2339-2360

Ponis S T, Koronis E (2012). Supply chain resilience: Definition of concept and its formative elements. Journal of Applied Business Research, 28(5): 921-929

Ponomarov S Y, Holcomb M C (2009). Understanding the concept of supply chain resilience. International Journal of Logistics Management, 20(1): 124-143

Rezapour S, Farahani R Z, Pourakbar M (2017). Resilient supply chain network design under competition: A case study. European Journal of Operational Research, 259(3): 1017-1035 
Rice J B, Caniato F (2003). Building a secure and resilient supply network. Supply Chain Management Review, 7(5): 22-30

Simangunsong E, Hendry L C, Stevenson M (2012). Supply-chain uncertainty: A review and theoretical foundation for future research. International Journal of Production Research, 50(16): 4493-4523

Tukamuhabwa B R, Stevenson M, Busby J, Zorzini M (2015). Supply chain resilience: Definition, review and theoretical foundations for further study. International Journal of Production Research, 53(18): $5592-5623$

Wieland A, Marcus Wallenburg C M (2013). The influence of relational competencies on supply chain resilience: A relational view. International Journal of Physical Distribution \& Logistics Management, 43(4): 300-320

Yu W, Jacobs M A, Chavez R, Yang J (2019). Dynamism, disruption orientation, and resilience in the supply chain and the impacts on financial performance: A dynamic capabilities perspective. International Journal of Production Economics, 218: 352-362

Zouari D, Ruel S, Viale L (2021). Does digitalising the supply chain contribute to its resilience? International Journal of Physical Distribution \& Logistics Management, 51(2): 149-180 